\title{
$\mathrm{R} \& \mathrm{D}$ 성과물 공동할용에 대한 연구자들의 인식에 관한 연구
}

\section{Perceptions of Researchers on Cooperative Utilization of Research Outcomes}

\author{
장 덕 현*노 류 하** 이 수 상*** \\ DurkHyun Chang • RyuHa Roh • Soo-Sang Lee
}

\section{차 례}
1. 서 론
3. 결 론

2. 연구성과물의 공동활용을 위한 조사

- 참고문헌

\section{초 록}

최근 학술커뮤니케이션에 나타난 변화 중 괄목할 만한 것이 '오픈액세스(Open Access)인데, 세계 적으로 정보공유를 위한 연구자들의 참여와 학계와 정부에서의 지원 정책 발표가 이어면서 서구를 중 심으로 급속히 확산되고 있다. 정보공유에 있어서 가장 중요한 것은 정보의 생산자이면서 소비자인 연 구자들의 참여의지와 인식이다. 따라서 연구성과 정보의 공유에 대한 인식 조사는 대단히 긴요하다. 본 조사는 특정 주제 분야의 연구자들을 대상으로 오픈액세스 환경에 대한 인식도를 조사하였다. 이 조사를 바탕으로 오픈액세스 환경에서 이슈가 되고 있는 저작권 문제를 조명하였다. 결과적으로 국내 연구자들에게 있어서 '오픈액세스'에 대한 인식은 아직은 미비한 것으로 나타난 반면, 저작권이 침해 되지 않는 범위 내에서 명확한 출처를 밝히고 합법적인 목적으로 연구물을 사용한다면 오픈액세스 활 동에 참여할 의사를 가지고 있는 것으로 조사되었다. 이러한 결과를 바탕으로 이 논문에서는 저작권과 라이선스의 마련, 그리고 산재한 연구성과물의 원활한 관리와 접근 및 활용을 극대화시킬 수 있는 연 구정보관리 체제의 구축이 필요함을 밝혔다.

\section{키 워 드}

오픈액세스, 개방접근, 저작권, 정보공유

* 부산대학교 문헌정보학과 부교수

(Associate Professor, Pusan National Univrsity, dchang@pusan.ac.kr)

** 한국학술진흥재단 지식정보센터 연구원

(Researcher, Korea Research Foundation, queencrystal@hanmail.net)

*** 부산대학교 문헌정보학과 조교수

(Assistant Professor, Pusan National University, sslee@pusan.ac.kr)

- 논문접수일자: 2008년 11월 4일

- 게재확정일자: 2008년 12월 13일 


\begin{abstract}
The purpose of this study is to scrutinize the copyright issue under Open Access environment. A survey has been carried out to investigate researchers' awareness and recognitions about such issues. For this, bioinformatics researchers were selected and surveyed. Descriptive statistics method is employed for analysis of collected data. The findings of this study summarized as follow. (1) Although the researchers regarded the Open Access a positive initiative, the perceptions about open access were very low. (2) The researchers demanded possession of copyright depending on type of research information. (3) Many agencies did not required the transfer of copyright to the researcher. Thus, there is a possibility of dispute regarding copyright issues between researchers and agencies. (4) The researchers are willing to participate in open access activity on the assumption that their study is used in legitimate objective. On the basis of these findings, suggestions are added in as an impetus to lower the barrier against a copyright and higher the approach to information seekers and information providers.
\end{abstract}

\title{
KEYWORDS
}

Open Access, Copyright, Free Access to Information

\section{1. 서론}

\section{1 연구의 배경과 목적}

정보사회에 있어서의 지식과 정보의 유통현 상은 양면성을 지닌다. 정보란 독립적으로 존 재하는 개체가 아니라 사회의 구조와 문화에 깊이 영향을 받는다. 즉 정보의 중요성이 증대 할수록 정보의 자유로운 활용에 의한 지적 활 동(intellectual activities)이 활성화될 수 있 는 반면, 사회 기득권층의 정보독점으로 인한 사회적 불평등이 심화될 수도 있다. 정보의 자
유로운 생산과 유통을 위한 장치들에도 불구 하고 정보의 상품화는 가속화되고 있는 현실 속에서 적절한 가격을 지불해야만 원하는 정 보를 구할 수 있는 것이 많은 경우 사실이다. 정보사회의 이러한 양면성은 정보정책에 있어 서도 중요한 함의를 지닌다. 즉, 정보의 공공 성을 강화하면 정보생산자의 권리는 제약받게 되며, 정보의 사유성에만 초점을 두면 정보격 차는 더욱 커질 것이다.

이는 학술거뮤니케이션(Scholarly Communication)에 있어서도 중대한 영향을 미친다. 17 세기 중엽 학술지(journal)라는 매체가 등장하 
면서 학술커뮤니케이션이 독립적 영역을 구축 한 이후 수세기 동안 많은 연구자들이 학술지 에 논문을 발표하고, 학회나 출판사, 그리고 도서관과 같은 장치들을 통하여 학술정보를 유 통시켜 왔다. 학술지는 기본적으로 독점적인 성격이 있다. 학술지에 논문을 게재하는 것은 연구 영역을 먼저 확보하고, 그 성과를 널리 알리기 위한 것이며 동시에 연구자의 업적을 평가받는 수단으로도 이용된다(신은자 2001). 원칙적으로 연구자는 그가 생산한 학술정보에 대한 권리를 지닌다. 그러나 대부분의 학술지는 연구자의 논문을 수록하는 대가로 연구자에게 저 작권의 양도를 요구한다. 학회는 기하급수적으로 늘어나는 학술논문들을 선별, 취합하여 학술지에 수록하는데, 그 효율을 기하기 위하여 출판 및 배포를 출판사에 아웃소싱하고, 학회와 출판사가 다시 관련 기업에 논문의 데이터베이스서비스를 허락하면서부터 학회에 양도되었던 연구자들의 저작권은 이러한 영리 기관에게 배타적으로 양도 되고 있다. 출판사나 원문데이터베이스회사는 연 구자들로부터 양도받은 저작권을 바탕으로 저널 의 독점적 성격을 활용하여 가격을 상승시키며, 이러한 경향은 과학-기술-의학(STM) 분야에서 두드러진다. 결국 이러한 기관들이 제시하는 높 은 구독료를 감당할 수 없는 개인이나 도서관은 학술정보의 이용으로부터 차단된다. 또한 연구자 들은 다른 사람들에게 자신의 저작물을 자유롭게 제공할 수 없게 되고, 저작물을 생산한 연구자조 차 자신의 저작물을 사용하기 위해 출판사(혹은 원문데이터베이스 회사)에 비용을 지불해야하는
모순이 생겨나는 것이다.

이러한 현행 학술커뮤니케이션의 모순을 극 복하기 위한 대안 중의 하나가 '오픈액세스 (Open Access)'인데, 현재 세계적으로 정보공 유를 위한 연구자들의 참여, 학계와 정부에서 의 지원 정책 발표가 이어지고 있는 실정이다. 2003년 6월 미국에서 정부의 자금을 지원받 아서 수행된 연구보고서 및 관련 연구 산출물 을 자유롭게 이용할 수 있도록 하자는 '과학에 대한 공공접근법(Public Access Science Act)' 을 추진한 이래(Sabo, Martin Olav 2003), 2004년 1월 파리에서 개최된 경제협력개발기 구의 과학기술정책위원회에서도 공공기금으로 수행된 연구성과에 대해 자유롭게 이용할 수 있도록 하자는 논의가 있었다(OECD 2004). 2004년 7월 영국에서는 자국의 고등교육기관 에서 생산된 연구보고서는 일반인들이 자유롭 게 이용할 수 있도록 정부가 적극 지원해야 한 다는 보고서가 발표되었다(House of Commons Science and Technology Committee 2004). 특히, 2008년 미국에서는 SPARC(Scholarly Publishing and Academic Resources Coalition), Students for Free Culture, 그리고 PLS(Public Library of Science)가 주관하여 10월 14일을 최초의 Open Access Day로 지 정하기도 하였으며, 같은 날 Open Access Scholarly Communication association이 발족하는 등 급속히 확산되고 있다. 국내에서 도 한국과학기술정보연구원의 국가 R\&D 종합 정보시스템기반구축사업과 '국가학술연구 $\mathrm{DB}$ 구 
축사업'의 일환으로 한국교육학술정보원이 추 진한 'dCollection' 사업, 그리고 학술진흥재 단의 오픈액세스 포럼 등을 예로 들 수 있다.

이러한 상황에서 연구성과물의 정보공유에 대한 조사는 대단히 긴요하다. 본 조사는 이러 한 인식을 바탕으로 특정 주제 분야의 연구자들 을 대상으로 오픈액세스 환경에 대한 인식도를 조사하였다. 이 조사를 바탕으로 오픈액세스 환 경에서 이슈가 되고 있는 저작권 문제를 조명하 고 나아가 문제를 해결하기 위한 방안을 제시하 는 기초자료를 제공할 수 있을 것이다.

\section{2 오픈액세스 저작권 관리 활동}

오픈액세스는 '장벽이 없는 온라인 정보 접 근'이라 정의할 수 있지만, 이를 위해서는 현 실적으로 두 가지 장벽이 존재하고 있다. 첫째 는 접근 비용의 장벽으로 정보 접근에 필요한 라이선스 비용, 회원료 등 톨게이트(toll-gate) 비용에 대한 장벽이고, 둘째는 접근 허용의 장 벽으로 저작권, 라이선스, 저작권관리(DRM) 등의 접근 및 사용에 대한 제한을 의미한다. 따라서 오픈액세스의 관건은 이 두 가지 장벽 을 없애거나 최소화하는 것이다(이수상 2003).

학술영역에서의 오픈액세스는 단순히 학술 논문을 디지털 보관시스템에 등록하거나 오픈 액세스 저널에 투고하는 행위만으로 충분하게 실현되는 것은 아니다. 중요한 것은 학술논문 에 대한 저작권을 일반대중에게 양도해야 하 기 때문이다. 즉, 일반대중이 학술논문에 쉽게
접근하고, 활용하는데 요구되는 각종 라이선 스(이용허락)를 부여받아야 한다는 의미이다. 이렇게 볼 때 오픈액세스 운동이 정보의 원활 한 유통에 일정정도 기여하는 것은 사실이지 만 이에 대한 가장 큰 저항세력은 아마도 기존 의 학술유통 영역에서 주도권을 가지고 있는 상업적 출판사, 데이터베이스 제공회사, 학회 등과 같은 이해관계자들일 것이다.

사실 오픈액세스는 기존의 저작권 개념에 변 화를 요구하고 있다. 최근 저작권은 컴퓨터 기술 의 발달과 아날로그 저작(도서, 만화, 음반, 영 화, 방송, 신문)들이 디지털화됨에 따라 '콘텐트 가 저작권자의 동의 없이 무단으로 사용될 경우 발생할 수 있는 저작권자의 손실을 방지하기 위 해 법으로 정한 저작권자의 권리 집합으로서 콘 텐트에 대한 사용, 조작, 분배 권리와 다른 사람 에게 권리를 위임할 수 있는 권리들을 포함'하는 것으로 정의되고 있다. 이에 따라 학술논문에 대 한 저작권 자체보다는 학술논문에 접근하는 방 식을 다르게 한다. 이해관계자들은 저작권을 통 해 자신들의 이익을 보호받는 범위 내에서 접근 을 허용하려 할 것이고, 저자는 자신의 연구결과 물을 다른 사람들이 사용하는데 있어 과도한 통 제를 가하는 것에는 찬성하지 않게 되는 것이다.

\section{3 연구의 내용}

\section{가. 조사대상}

본 조사에서는 생물정보학 분야를 대상으로 연구자들의 오픈액세스에 대한 인식과 정보의 
자유로운 유통 활동에 대한 참여의사를 조사 하였다. 생물정보학(bioinformatics)은 다양 한 세부분야를 포괄하고 있지만, “생명현상 연구에 필요한 다양한 전산학 - 통계학 - 수학적 접근”이라고 정의할 수 있다(원세연 2000). 즉, 생물학 관련 데이터를 컴퓨터로 정리 - 분 석-이용하는 방법을 연구하는 학문으로, 다 양한 생명체를 대상으로 유전자의 염기 서열 데이터 분석·해석에 응용되고 있다. 현재 인간 게놈지도의 발표를 계기로 생물정보학에 대한 중요성이 널리 인식되고 있으며, 이는 불치병 만성병의 원인과 치료방법을 제공할 21 세기 유망 학문의 하나로 각광받고 있다.

우리나라에서는 1998년에 한국생물정보학 회(KSBI: Korean Society for Bioinformatics)가 발족하였고 최근에는 생물정보학 과, 바이오시스템(Biosystems)학과 등이 신설 되어 교육과 연구가 증진되고 있다. 국내의 생 물정보학은 인프라 구축이나 관련 기업들의 역량 등 여러 면에서 선진국에 미치지 못하고 있는 상황이며, 특히연구결과의 통합 및 관리 면에서 취약한 수준이다(과학기술부 2003). 2008년 현재 한국학술진흥재단의 한국연구업 적통합정보(구.통합연구인력정보)에 전공분야 를 '생물정보학'으로 명시하고 있는 연구자는 총 62 명이다. 또, 한국생물정보학회에 따르면 약 500 명 정도가 활발하게 활동하는 학회원 (active member)으로 파악되었다. 본 조사는 2005년 9월 부산 벡스코(BEXCO)에서 열린 '2005 국제생물정보학술대회(BIOINFO)' 에
참가한 학회원 300 여 명을 대상으로 한 설문 의 내용을 분석한 것이다. 분석은 1 차 현장 회 수 76 부, 2 차 E-mail회수 28 부로 총 104 부 가운데 분석에 적절하지 않는 2 부의 데이터를 제외한 102 부를 대상으로 이루어졌다.

\section{나. 조사방법}

조사는 크게 두 영역으로 이루어졌다. 우선 연구성과물의 저작권 관리에 대한 일반적인 사항을 조사하기 위하여 생물정보학 분야 연 구자들이 대다수 소속되어 있는 주요 연구소 와 대학을 중심으로 저작권 관리 실태와 관련 된 원자료 연구와 관련 웹사이트의 내용조사 를 수행하였으며, 담당자와의 전화 인터뷰를 시행하여 자료를 보완하였다.

이어서 자원공유에 대한 연구자들의 인식조 사를 위하여 고정형 선택지에 의한 질문(fixed -alternative question)이 사용되었다. 질문 지 구성형식의 유형은 선다형식(method of multiple choice)과 가부질문형식(method of dichotomous question), 평정척도형식(rating scale methods)으로 이루어졌으며, 수집된 자 료는 기술통계(descriptive statistics)로 분석 하였다.

\section{다. 용어의 정의}

1) 연구성과물

연구성과물은 연구자의 학술활동 및 연구개 발로 산출된 모든 형태의 정보자원을 지칭한 다. 이는 연구 비용의 제공원에 따라 '기금 지 
원에 의한 연구'와 '개인비용에 의한 연구'로 나눌 수 있다. 전자는 연구보고서를 생산, 납 본하는 경우이며, 후자는 연구보고서의 생산 및 납본이 필요하지 않은 경우로서 연구의 결 과를 연구보고서 이외의 학술적 매체(주로 단 행본이나 학술논문)로 생산 - 배포한다. 본 연 구에서의 '연구성과물'은 연구보고서를 생산, 납본하는 조건으로 기금을 지원받은 연구 활 동 과정에서 생산된 연구물을 의미한다. 주로 정부기관이나 정부출연기관, 대기업체가 연구 주관기관이 되어 연구비를 제공하고 대학부설 연구소나 관련 학술단체, 정부출연연구기관, 개인연구자 등이 연구한 결과를 바탕으로 생산 되는 모든 정보 자원을 지칭하는 것이다(최은 주 2008). 연구정보는 연구물의 유형에 따라 다음과 같이 세 가지 유형으로 구분할 수 있다.

(1) 사전연구물 : 최종 연구보고서 발행 전에 생산 되는 연구물로 연구제안서, 연구계획서(research proposal), 중간보고서(interim report), 세미나, 워크숍·학회 발표자료 등이 있다.

(2) 연구보고서: 연구과제 완료 후 최종적으로 작성되어 과제기관에 제출하는 보고서로 최종보고서(final report)가 있다.

(3) 사후연구물: 연구보고서를 축약, 수정-보 완하여 전문 학술지에 투고하는 논문, 단 행본 또는 단행본 형태의 보고서 세미나 및 워크숍·학회 발표자료 등의 연구물을 의미한다.

\section{2. 연구성과물의 공동활용을 위한 조사}

\section{1 조사대상의 인구통계학적 분석}

\section{1) 설문대상자의 인적사항}

설문대상자의 직업 분포는 교수 27 명, 연구소 연구원 50 명, 대학원생 25 명으로 집계되었다 (〈그림 1〉참조〉). ${ }^{1)}$

〈그림 2)는 설문대상자의 연령에 따른 분 포인데, 연령에 따라 정보 공유 인식이나 이용 행태가 별다른 차이를 보이고 있지는 않았다. 설문대상자의 연령은 30 세 미만이 $39 \%$ 로 가

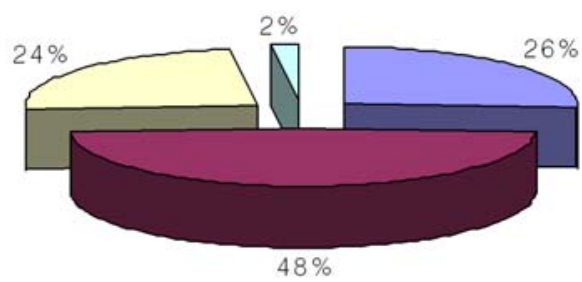

$\square$ 교수 $\square$ 연구원 $\square$ 대학원생 $\square$ 기타

〈그림 1〉 설문대상자의 직업에 따른 분포

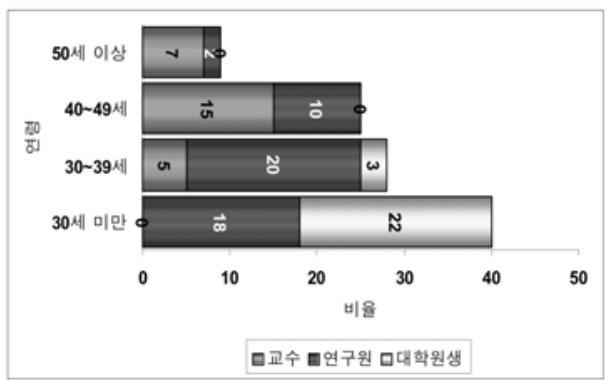

〈그림 2〉 설문대상자의 연령에 따른 분포

1) 교수는 일반 대학교수와 함께 기금교수, 시간강사 등을 포함한 것이며, 대학원생은 현재 석·박사 과정 재학 중인 자로 제한했다. 대학원에 재학 중이지만, 강의를 하거나 연구소에 재직 중인 자는 원직 기재를 원칙으로 하였다. 
장 많았으나, 이는 대학원생들이 다수를 차지 하는 것이 이유였다. 연구 활동이 가장 활발할 것으로 예상되는 30 대, 40 대 연구자들은 각각 $28 \%$ 와 $25 \%$ 로 비교적 비슷한 비율을 보였다.

\section{2 연구성과물의 저작권에 관한 분석}

제 2 영역은 연구과제 수행시 생산되는 연구 성과물의 저작권에 관한 내용이다. 이는 연구 물의 유형에 따른 연구자들의 저작권에 대한 인식과 저작권 문제와 관련하여 연구자와 직 접 연관이 있는 각 기관에 대한 조사이다. 먼 저 연구과제와 관련된 일반적인 사항에 대해 서 알아보았다.

\section{1) 저작권의 귀속 문제}

연구물의 유형에 따른 연구자들의 저작권에 대한 인식과 저작권 문제와 관련된 입장에 대 한 조사이다. 먼저 연구자들이 연구성과물의 저작권이 누구에게 귀속된다고 생각하는지 알 아보았다.

연구정보의 유형은 앞에서 정의한대로 3 가 지로, 사전연구물의 경우, 전체 응답자의 $72 \%$ 가 연구자 본인에게 저작권이 있음을 표명했 다. 하지만 연구원들은 $32 \%$ 가 연구자의 소속 기관이라고 답해, 다른 집단의 응답자들에 비 해 소속기관에 대한 소속감이 높음을 알 수 있 다. 기타, 연구자 본인과 소속기관의 공동 소유 임을, 또 다른 의견으로는 사전연구물은 저작 권등록을 할 수 있는 상태가 아니므로 어느 누
구도 권한 주장을 할 수 없다는 의견도 있었다 (〈그림 3〉 참조).

연구보고서의 경우에도 연구자 본인에게 저 작권이 있음을 표명한 응답자가 $37 \%$ 에 달했 다. 그러나 이렇게 답한 응답자의 $42 \%$ 가 대학 원생으로, 대부분의 대학원생이 연구과제 제 안 및 계약을 직접 하지 않음을 감안할 때 다 소 비현실적이다. 연구보고서에 대해서는 연

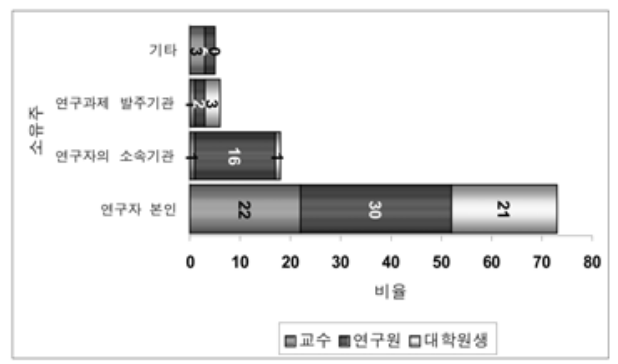

〈그림 3〉 사전연구물의 저작권

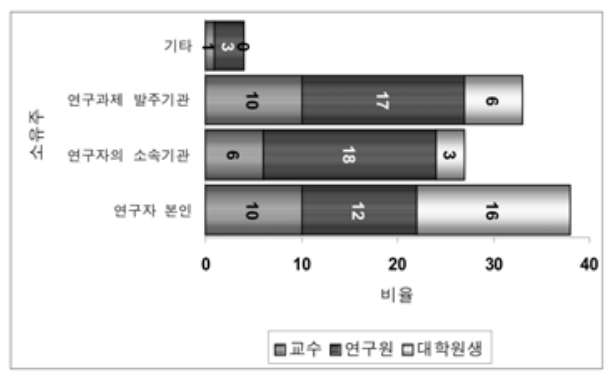

〈그림 4〉연구보고서의 저작권

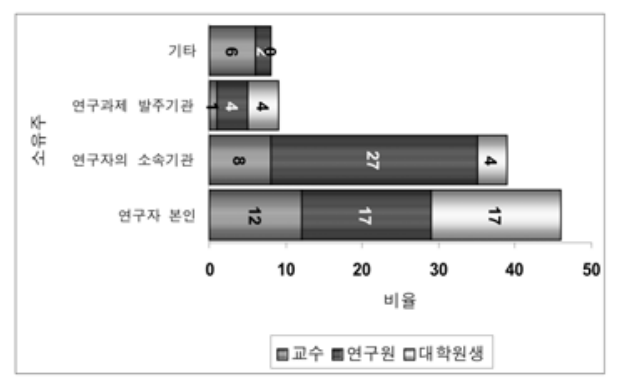

〈그림 5〉 사후연구물의 저작권 
구자의 소속기관(26\%)보다는 연구과제 발주기 관(32\%)에게 저작권이 있다고 생각하는 비율 이 조금 더 높았다. 이는 연구과제의 경우 발 주기관으로부터 위탁을 받은 연구이므로, 그 연구의 실질적인 결과는 발주기관이 소유해야 한다고 생각하는 경향이 높은 것으로 여겨진 다. 기타로 연구자 본인과 소속기관 또는 연구 자 본인과 연구과제 발주기관의 공동 소유라 는 의견도 있었다(〈그림 4〉참조〉).

사후연구물의 저작권에 대한 응답을 살펴보 면, 집단 간의 생각이 판이하게 다름을 알 수 있다. 연구원의 과반수 이상 $(54 \%)$ 이 소속기관 이라고 말한 반면, 이렇게 답한 교수집단은 $30 \%$ 에 그쳤다. 또한 교수의 $44 \%$ 는 사후연구 물의 저작권의 소유는 연구자 본인에게 있다 고 하였으나, 연구원은 $34 \%$ 만이 같은 응답을 하였다. 이는 교수들이 다소 독립(단독)적인 연구자라고 생각하는 경향이 높음을 보여주는 반면, 연구원은 소속기관에 속해 있는 집단(공 동)적인 연구자라고 생각하는 경향이 높음을 보여준다. 기타 의견으로 연구자 본인과 소속 기관, 연구자 본인과 연구과제 발주기관, 연구 자 본인과 소속기관연구과제 발주기관의 공동 소유 등 다양하게 나타났다(〈그림 5〉 참조).

위의 결과를 종합해보면, 사전연구물은 연 구자 본인, 연구보고서는 연구과제 발주기관, 사후연구물은 연구자본인이나 연구자의 소속 기관에 저작권이 있다고 생각하는 경향이 두 드러졌다. 이러한 결과는 제 $3 \cdot 4$ 영역의 결과 와 더불어 연구과제 수행과정에서 파생되는
연구물의 저작권 관리에 대한 방안을 마련하 는 토대가 될 것이다.

\section{2) 저작권 귀속 기관의 문제}

다음은 저작권 문제와 관련하여 각 기관의 입장에 대한 조사이다. 우선 소속기관의 경우, 임용시 저작권 양도계약을 체결한 응답자는 전체의 $21 \%$ 에 지나지 않았다. 서면으로 기록

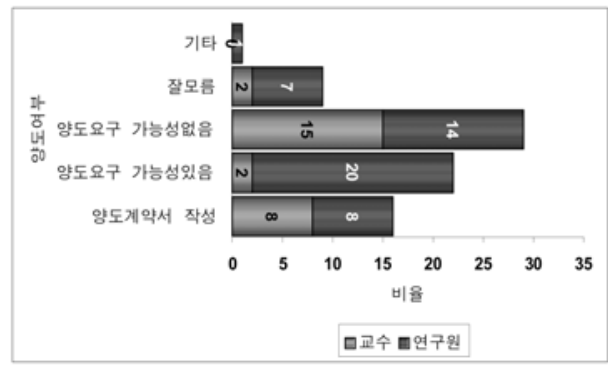

〈그림 6〉 소속기관과 저작권

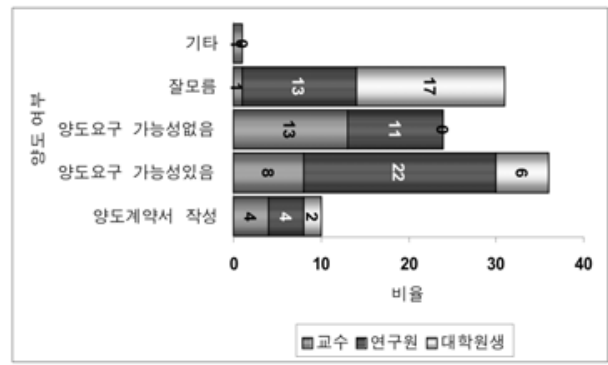

〈그림 7〉연구과제 발주기관과 저작권

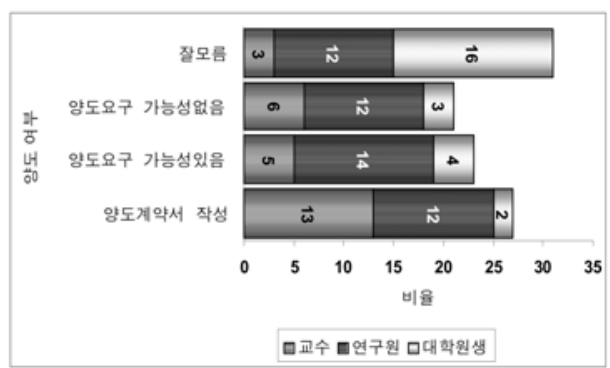

〈그림 8〉 학회와 저작권 
하지는 않았으나 저작권 양도를 요구할 것 같 다고 답한 응답자는 $29 \%$ 였으며, 이들의 $91 \%$ 가 연구원으로서, 이는 다른 집단에 비해 연구 원들의 소속성이 강함을 보여주는 결과이다. 반면, 양도 요구 가능성이 없음을 표명한 응답 자는 $38 \%$ 로 가장 높은 비율을 보였다. 하지만 저작권 양도 계약서를 체결했거나 양도를 요 구할 것 같다고 답한 응답자의 비율이 전체의 $50 \%$ 이므로, 연구자와 소속기관 사이의 저작 권에 관한 적절한 지침이 필요할 것으로 보인 다. 기타로 임용 계약 시 저작권 양도를 요구 하지 않으나, 특허 출원 시에는 재산권 포기를 요구한다는 의견도 있었다(〈그림 6〉 참조).

다음은 연구과제 발주기관과 연구자 간의 저 작권 문제에 대한 것이다. 이는 과제 계약시 연 구자가 생산한 연구물에 대해 발주기관이 저작권 양도를 요구하는지를 알아보기 위한 문항이다.

연구과제 계약 시, 전체 응답자의 $10 \%$ 만이 저작권 양도 계약서를 작성했다고 답했다. 그 리고 서면상으로 작성하지는 않았으나, 저작 권 양도를 요구할 것 같다는 응답이 $35 \%$ 로 가 장 많은 비율을 차지했다. 연구과제의 경우 발 주기관으로부터 위탁을 받은 연구이므로, 그 연구의 결과에 대한 소유권을 발주기관에서 요구할 수도 있을 것이라는 생각을 보여주고 있다. 이는 연구과제 수행 후 발주기관과 연구 자 사이에서 저작권 분쟁이 생길 소지가 있을 것으로 예상된다. 따라서 발주기관과 연구자 사이를 정리해 줄 저작권 관련 지침이 필요하 다고 할 수 있다. 한편, 잘 모르겠다는 의견이
$30 \%$ 에 달해 그 뒤를 이었으나, 이렇게 답한 응답자의 $55 \%$ 가 대학원생으로 이 역시 연구 과제 계약당사자가 아니기 때문에 나타나는 결과임을 알 수 있다(〈그림 7〉 참조).

다음은 연구과제에서 파생된 사후연구물을 학술지에 투고할 경우 이에 대해 학회가 저작 권 양도를 요구하는지에 대한 질문이다. 이에 대한 응답은 2 30\% 내외로 비슷한 비율로 나 타났다.

생물정보학 분야 연구자들의 국내 저널 투 고율은 그다지 높지 않은데, 이는 저널의 종류 가 적을 뿐 아니라, 외국 저널에 비해 국내 저 널의 논문 투고에 대한 인지도가 낮기 때문이 다. 이것은 일반적인 과학기술 분야의 특성이 라 할 수 있겠다. 생물정보학 분야의 대표적인 학회인 한국생물정보학회에서는 현재 학회지 를 발행하지 않으며, 생물정보학 분야의 연구 자들이 주로 투고하는 학회는 한국생물정보학 회(http://www.ksbi.or.kr), 한국정보과학회 (http://www.kiss.or.kr), 대한약학회(http:// www.psk.or.kr), 한국퍼지 및 지능시스템학 회(http://www.fuzzy.or.kr), 대한의생명과 학회(http://biomed.web.riss4u.net), 한국생 화학분자생물학회(http://www.ksmbmb .or.kr), 한국미생물생명공학회(http://www. kormb.or.kr), 한국미생물학회(http://www. msk.or.kr), 대한내분비학회(http://www.end ocrinology.or.kr) 등이다. 이 학회들의 논문 투고규정을 보면, 한국정보과학회를 제외한 나 머지 8개의 학회는 모두 '게재된 논문의 저작 
권은 본 학회에 귀속된다' 또는 '학회지의 게 재는 원고의 저작권이 저자로부터 학회지로 이양되는 것을 저자가 승인한 것으로 인정한 다'는 조항을 밝히고 있다.

그럼에도 불구하고 저작권 양도계약서를 작 성했다고 답한 응답자는 $26 \%$ 에 불과했으며, 서면상의 기록은 하지 않았지만 학회가 저작 권의 양도를 요구할 것이라고 응답한 경우도 $23 \%$ 에 지나지 않았다. 반면에 과반수 이상 (51\%)이 '양도요구 가능성이 없다' 또는 '잘 모르겠다'고 응답하였다(〈그림 8〉 참조). 해당 학회의 관련자들과의 전화인터뷰를 통해서 파 악된 바에 따르면, 논문의 게재가 확정되는 순 간 자동으로 원고의 저작권이 저자로부터 학 회로 이양되는 데 대하여 연구자들이 그다지 신경을 쓰고 있지 않음이 주된 원인이었다.

이는 저자와 학회간의 직접적인 저작권 양 도 체결 과정이 생략되었기 때문에 나타나는 현상이다. 학회에서는 투고규정에 저작권 양 도에 대한 지침을 밝히고 있지만, 직접적인 저 작권 양도 절차가 없어 정작 저자들은 원고의 소유주가 달라진 것을 모르는 것이다. 학회측 에서는 저작권에 대한 연구자들의 무관심을 원인으로 지적하고 있었지만, 이러한 문제의 원인에는 연구자들뿐만 아니라 학회의 저작권 업무에 있어서의 안일함 또한 원인으로 저작 권과 관련하여 학회의 적극적인 홍보가 필요 함을 시사한다.

위의 결과와 해당 기관들에 대한 전화인터뷰 를 종합해 보면, 현재로서는 대부분의 기관들이
연구성과물의 귀속 및 지적재산권의 승계에 대 한 규정을 가지고 있기는 하지만, 주로 특허 관 련 사항에 머무르고 있으며 저작권의 경우에 있 어서는 연구자들에게 저작권 양도를 엄격하게 요구하지는 않고 있는 것으로 나타나고 있다. 그럼에도 불구하고 연구자들은 저작권 양도 계 약서를 작성했다고 인식하거나 혹은 요구할 가 능성이 있다고 응답한 경우가 $50 \%$ 내외로 나타 나, 향후에 연구자와 각 기관들 사이에서 저작 권 분쟁의 소지가 있는 것으로 사료된다.

\section{3 정보생산자의 입장에서 본 연구성과 물의 공개와 유통}

이 영역은 연구자 본인이 생산한 연구정보의 공개 및 유통에 관한 분석이다. 이 영역의 조사 결과로 인해 오픈액세스 환경에 대한 국내 생 물정보학자들의 전반적인 인식과 정보공유에 대한 참여 의사를 확인할 수 있을 것이다.

제 3영역에서는 〈그림 9〉 〈그림 11〉을 제 외한 문항들을 중복응답이 가능하도록 하였

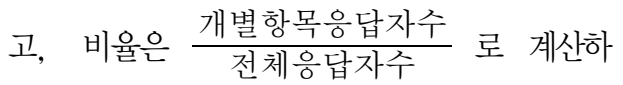
여 표기하였다.

\section{1) 응답자의 연구성과물 이용 방법}

다음은 연구자 본인이 생산한 각 연구성과 물의 이용방법에 관한 문항이다.

응답자의 사전연구물을 이용할 수 있는 방 법으로는 연구동호회나 세미나 발표와 같은 오 프라인을 통한 접근(34\%)이 가장 높은 비율을 
차지했다. 다음은 요청시 e-mail을 통한 배포 (31\%)였다. 이는 조직내부(소속기관이나 연구 과제 발주기관)에서만 유통되는 경우가 많은 사전연구물의 특성상, 아무런 규제없이 온라 인으로 어느 누구나 접근할 수 있는 종류의 정 보는 아님을 보여준다. 또한 아래의 다른 형태

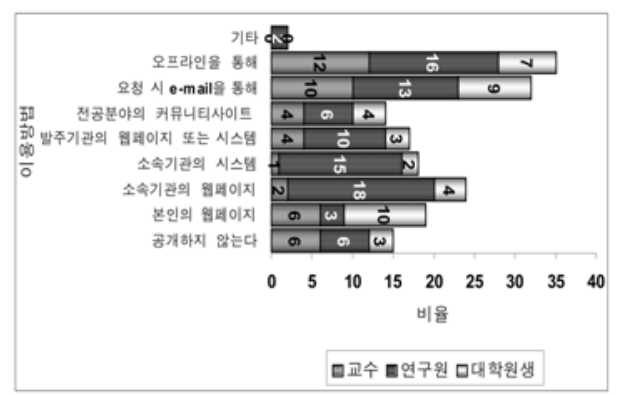

〈그림 9〉 응답자의 사전연구물 이용방법

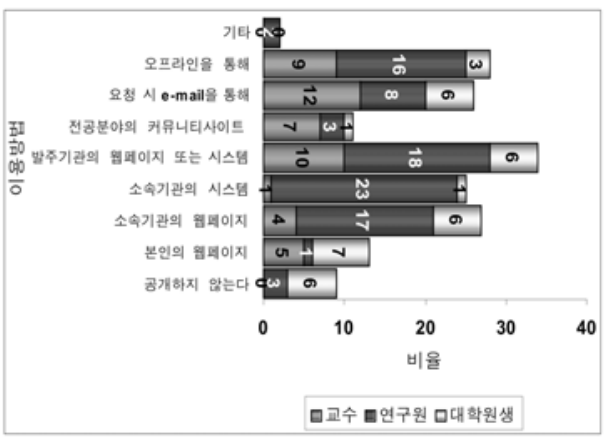

〈그림 10〉응답자의 연구보고서 이용방법

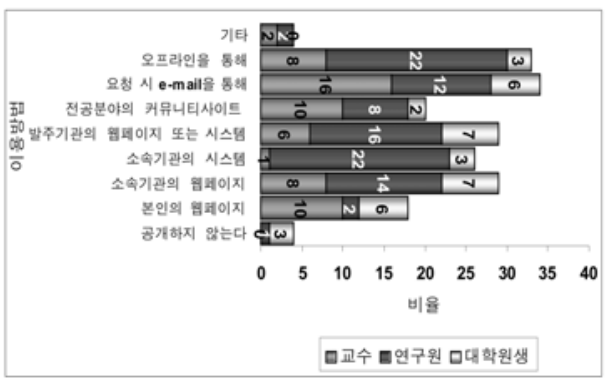

〈그림 11〉 사후연구물 이용방법
의 연구정보에 비해 '공개하지 않는다(15\%)' 는 답변이 다소 높은 비율을 차지하였다. 이는 사전연구물이 주로 연구분야 선점을 위한 경 쟁정보(competitive intelligence)의 성격이 강하기 때문인 것으로 분석된다(〈그림 9〉 참조).

다음은 응답자의 연구보고서를 이용할 수 있 는 방법이다. 연구과제는 연구자가 발주기관으 로부터 위탁을 받아 수행하므로 연구보고서는 과제 발주기관의 웹페이지나 시스템을 통해 $(33 \%)$ 이용 가능한 것으로 여겨졌다. 다음은 연구동호회나 세미나 발표와 같은 오프라인을 통한 방법(27\%), 소속기관 또는 부서의 웹페이 지(26\%), 소속기관 또는 부서에서 운영하는 시 스템(25\%) 등을 이용한 방법이 비슷한 비율로 나타났다(〈그림 10〉참조). 이번 문항은 각 집 단 간의 경향이 판이하게 다른데, 공통적으로 높은 비율을 차지한 과제 발주기관의 웹페이지 나 시스템을 통한 방법을 제외하면, 교수집단 은 오프라인과 e-mail을 통한 방법을, 연구원 집단은 소속기관의 웹페이지나 시스템을 통해 다른 연구자들에게 연구보고서를 제공하고 있 음을 보여주고 있다. 이는 '연구소'에서 '대학' 보다 조직원들의 연구정보에 대한 관리가 훨씬 더 조직적으로 이루어지고 있음을 의미한다.

다음으로, 사후연구물의 경우는 연구보고서 를 축약 및 수정·보완하여 전문 학술지에 투고 하는 논문, 개별주제보고서, 단행본 또는 단행 본 형태의 보고서, 세미나 및 워크솝학회 발 표자료 등의 연구물로 주된 이용 방법은 요청 시 e-mail을 통한 방법(33\%)과 오프라인을 
통한 방법(32\%)으로 나타났다. 요청시 e-mail 을 통해 연구물을 제공한다는 것은 저자가 요 청자의 신분과 정보이용 목적 등을 확인 한 후 정보를 제공하겠다는 것으로 합법적으로 사용 된다면 정보를 공유할 의사가 있음을 나타내 고 있다. 다음으로 소속기관의 웹페이지(28\%) 나 시스템(25\%), 연구과제 발주기관의 웹페이 지나 시스템을 이용한 방법(28\%) 등이 비슷한 비율을 이루었다(〈그림 11〉 참조).

이번 문항 역시 직업군을 나누어 분석하면, 교수들은 본인의 웹페이지나 전공 분야의 커 뮤니티사이트 등을 통한 방법을, 연구원은 여 전히 소속기관의 웹페이지나 시스템 혹은 발 주기관의 웹페이지나 시스템을 통해 연구정보 를 제공하고 있는 것으로 나타났다.

연구자의 '사전연구물-연구보고서-사후연 구물 이용방법'에 대한 인식조사의 결과를 종 합해 볼 때, 세 가지 연구정보의 유형 중 '공 개하지 않는다'는 비율이 가장 높은 사전연구 물의 수집은 사실상 불가능한 것으로 판단된 다. 이들을 웹상에서 자유롭게 이용할 수 없다 면, 사전연구물을 이용하고자하는 이용자들을 만족시키고 오픈액세스 환경에서 효과적으로 연구정보를 제공 및 관리하기 위한 지침이 적 절하게 마련되어 있어야 한다.

\section{2) 정보생산자의 관점에서 본 오픈액세스에 대한 인식}

다음은 정보생산자의 관점에서 바라본 오픈 액세스에 대한 인식과 정보이용형태에 따른
사용권의 허용범위, 라이선스 제한 사항 등을 분석한 문항이다.

응답자의 연구정보가 웹상에서 자유롭게 유 통된다고 가정할 때, 가장 거리끼는 부분이 무 엇인지 묻는 문항이다. 응답자의 과반수 이상 이 인용표시를 하지 않는 표절(58\%)을 들었 다. 다음으로 많은 득표수를 받은 항목은 영리 목적의 사용(48\%)이었다. 많은 연구자들이 순 수한 비영리적인 의도로 수행하는 연구의 정 보가 영리적인 목적으로 사용되는 것을 원치 않았다(〈그림 12〉 참조).

다음은 저작권의 소유주와 상관없이 응답자 의 연구정보가 웹상에서 자유롭게 유통된다고 가정할 때, 응답자의 연구정보를 사용할 수 있 는 사용권의 허용 범위를 묻는 문항이다.

연구자가 제시한 8 개의 항목 중에서 5 개의 항목(전시, 출력, 발췌, 저장, 복사)은 사용권 의 허용 범위가 넓게 나타났다. 반면에 양도의 경우 $55 \%$, 수정은 $71 \%$, 매매는 무려 $79 \%$ 에 달하는 응답자가 허용할 수 없다고 답했다. 수 정과 매매의 경우 이미 거론되었던 문제이기 도 하다. 이는 영리적인 목적이나 내용변경을 통한 원본의 훼손이 없다면 연구정보를 자유 롭게 이용할 수 있도록 오픈액세스 활동에 참 여하겠다는 의사표현으로 간주해도 될 것이 다. 이 문항에 대해 집단 간의 차이는 보이지 않았다(〈그림 13〉 참조).

이어서, 〈그림 14〉는 정보생산자의 관점에 서 바라본 정보이용형태에 따른 사용의 제한 사항에 관한 것이다. 즉, 응답자의 연구정보가 
웹상에서 자유롭게 유통된다고 가정하고, 타 인이 응답자의 연구정보를 사용할 때, 제한하 고 싶은 항목에 대한 응답결과이다.

설문에서 지속적으로 거론되고 있는 것이 원본의 수정과 매매에 관련된 사항이다. 이 역 시 대다수의 응답자들이 원본을 훼손하지 않 을 것 $(74 \%)$ 과 학술적인 목적으로만 사용할 것 (84\%)을 가장 중요하게 여기고 있다. 사용횟 수의 제한이나 특정 그룹의 이용자에게만 공 개 또는 특정 지역의 이용자에게만 공개를 하 고 싶다는 의견을 피력하는 응답자도 $40 \%$ 에 달했다. 이는 전반적으로 정보공유에 참여는 하되, 자신이 생산한 연구정보의 무차별적인 공개를 꺼리는 것으로 보인다.

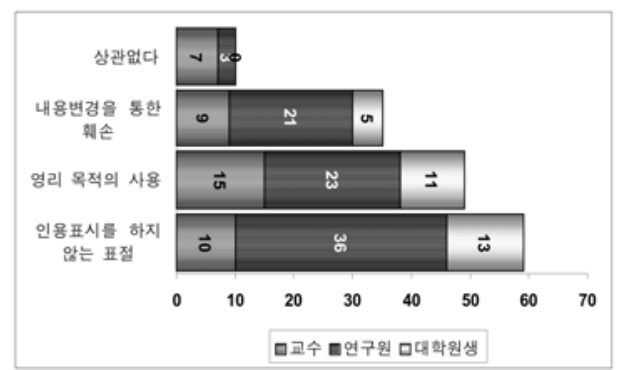

〈그림 12〉 오픈액세스에 대한 우려

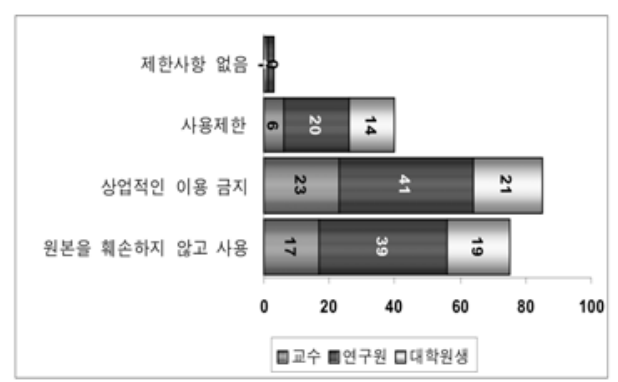

〈그림 14〉 정보생산자가 제시한 라이선스 제한 사항
제 3 영역의 마지막은 자유로운 공공정보의 유통에 대한 참여 의사를 확인하는 문항으로 〈그림 15〉는 오픈액세스를 통한 정보생산자의 정보공유 참여의사를 조사한 것이다.

응답자의 대부분은 연구물의 저자에 대한 명확한 표시(출처의 명시:83\%)를 한다면 정보 공유 활동에 참여할 의사가 있는 것으로 밝혀 졌다. 학술적인 목적으로 생산된 연구정보이 므로, 출처에 대한 명확한 표시를 한다면 기꺼 이 정보를 공유하겠다는 의미로 해석된다. 이 는 연구자들의 정보 공유 활동에 대한 참여율 을 높이기 위해 적절한 라이선스가 필요함을 말하고 있다. 또한 출처 명시를 제 1 조건으로 내세운 응답자 중 일부는 연구성과물이 생산

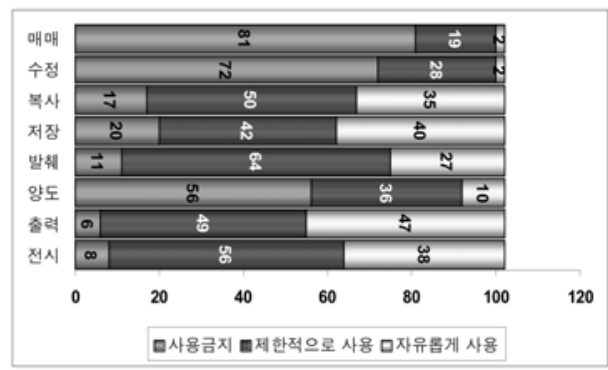

〈그림 13〉 정보생산자가 제시한 정보이용형태에 따른 사용권의 허용범위

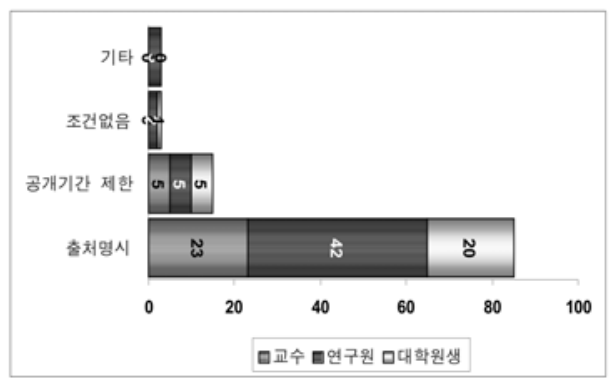

〈그림 15〉 정보생산자의 정보공유 참여의사 
된 일정기간 이후 또는 일정기간 동안만 사용 (15\%)할 수 있도록 엠바고(embargo)를 설정 하여 공개하겠다는 의견도 있었다.

\section{4 정보이용자의 관점에서 본 연구성과 물의 공개와 유통}

이 영역은 타 연구자들의 정보를 이용하는 정보이용자의 입장에서 정보이용행태와 타인 에게 기대하는 연구정보 공개 및 유통에 관한 분석이다. 앞서 분석한 제 3 영역과 비교하여 연구정보의 공개 및 유통에 있어서 정보생산 자와 정보이용자의 관점 차이를 조명한다.

\section{1) 정보이용행태}

〈그림 16〉은 연구자들의 정보이용행태에 관 련된 문항에 대한 응답결과를 정리한 것이다.

연구 진행시 주로 참고 혹은 인용하는 논문 은 3 5년 전(43\%)에 발표된 논문을 사용하는 경우가 가장 많았다. 다음은 2 년 이하( $29 \%)$ 의 논문을 사용한다는 의견이 뒤를 이었다. 이러 한 결과는 연구자들이 데이터의 즉시인용은

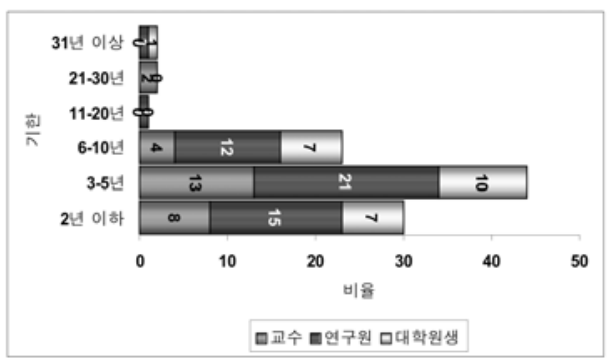

〈그림 16〉 참고 논문의 연령
높지 않지만 $70 \%$ 이상의 인용논문이 최근 5 년 이내에 출판된 것으로 상대적으로 최신의 데이터를 선호하는 것으로 나타났다.

〈그림 17〉은 제 3 자의 저작권에 관련된 문 항에 대한 응답결과이다. 여기서 제 3 자란, 연 구자가 다른 논문을 인용할 경우 대상 논문의 저자를 의미한다. 논문을 작성할 경우, 다른 연구자의 논문을 인용하는 것은 당연한 과정 이다. 하지만 대다수의 연구자들이 다른 연구 자의 논문을 인용하면서 인용부분의 저작권 문제에 대해서는 생각하지 않았을 것으로 보 인다. 이 문항은 응답자들이 제 3 자의 저작권 에 대해서 어떠한 인식을 가지고 있는지에 대 해 알아보기 위해 설계되었다. 인용부분의 출 처 표시와 관련하여 '표절' 문제가 제기될 가 능성이 항존하기 때문이다.

응답자의 $59 \%$ 가 각주나 참고문헌에 기재한 것만으로 사용 승인을 받았다고 생각하고 임 의로 사용한다고 답하였다. $27 \%$ 는 생각해 본 적 없다고 답했으며, 응답자 가운데 $9 \%$ 는 저 작자의 사용승인을 받는다고 대답했다. 기타 로 필요하다고 생각할 때만 저자와 상의한다

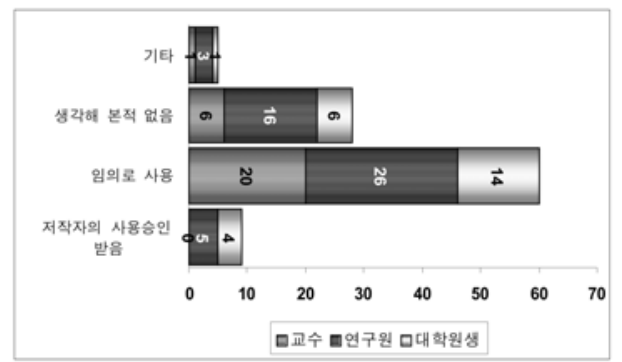

〈그림 17〉 제3자의 저작권 
는 의견도 있었다.

사실상 다른 연구자의 논문을 인용할 때마 다, 일일이 저자의 승인을 받는다는 것은 무리 가 있다. 더욱이 국내 논문의 인용보다는 국외 논문의 인용률이 훨씬 높은 과학기술 분야에 서는 거의 불가능하다. 따라서 제 3 자의 저작 권 문제는 합법적인 목적으로 사용하는 경우 명확한 출처를 표시하는 것으로 저작권자의 사용승인을 받은 것으로 해석해야 한다. ${ }^{2)}$

다음 〈그림 18〉은 타 연구자들의 정보를 이용하는 정보이용 행태에 관련된 마지막 문 항이다. 다른 연구자의 연구물을 이용할 수 있 는 방법으로는 전자저널(57\%)이나 전문 데이 터베이스를 통한 방법(53\%)이 우세를 보였다. 다음은 학회 또는 기관 데이터베이스를 이용 하는 방법(45\%), 인쇄본 복사나 도서관 대출 등 오프라인 방식(43\%), 검색포털을 통한 검 색(41\%) 등이 주류를 이루었다.

각 항목들간 비율지수가 별다른 차이를 보

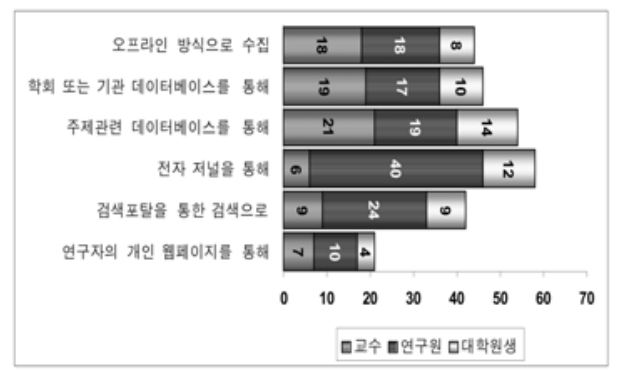

〈그림 18〉 다른 연구자의 정보를 이용하는 방법
이지 않고 있어 다른 연구자의 정보를 이용하 는 방법은 다양한 것으로 나타났다. 그러나 대 부분의 연구자들이 주로 웹상에서 정보를 찾 고 있고, 이러한 정보는 산재하고 있으므로 이 용자들이 필요로 하는 정보를 한곳으로 모으 는 것이 중요하다.

2) 정보이용자의 관점에서 바라본 오픈액세스 에 대한 인식

〈그림 19〉는 오픈액세스 환경에서 정보이 용자가 정보이용 형태에 따라 다른 연구자의 연구정보를 사용하기를 원하는 방식에 대한 질문이다.

연구자가 제시한 8개 항목 중에서 3 개의 항 목(전시, 출력, 발췌)에 있어서는 사용권의 허 용 범위가 넓게 나타났다. 반면에 양도의 경우 $46 \%$, 수정은 $75 \%$, 매매는 $79 \%$ 의 응답자가 이러한 용도로는 절대 사용하지 않겠다고 답 했다. 조사결과, 정보이용자의 관점에서 원하

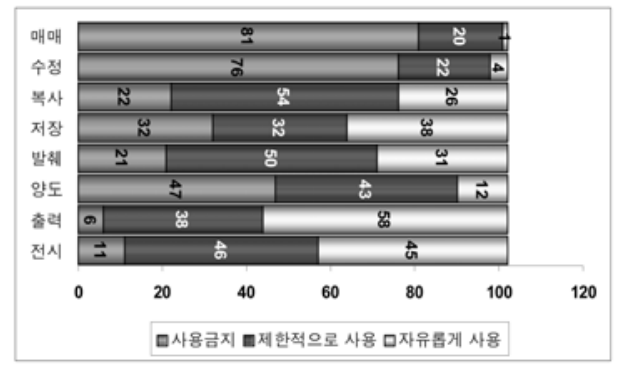

〈그림 19〉 정보이용자가 원하는 정보이용형태에 따른 사용권의 허용 범위

2) 현행 저작권법 제2장 제25조 ‘공표된 저작물의 인용’에서도 다음과 같이 명시하고 있다. - 공표된 저작물은 보도 비평·교육·연구 등을 위하여는 정당한 범위 안에서 공정한 관행에 합치되게 이를 인용할 수 있다. 


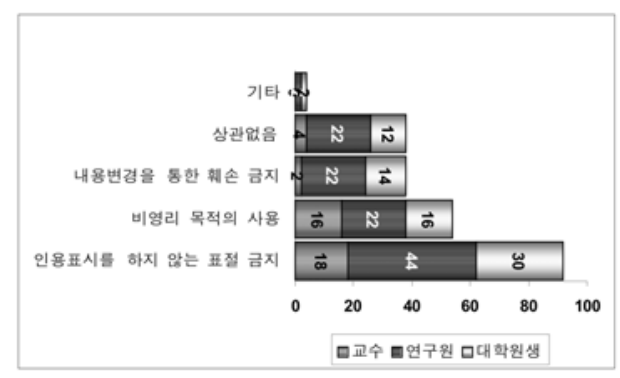

〈그림 20〉정보이용자가 원하는 오픈액세스 환경

는 정보의 이용범위는 정보생산자의 관점에서 바라본 사용권의 허용범위보다 좁게 나타남을 알 수 있었다. 이는 대부분의 연구자들이 타인 의 권리를 침해하지 않는 한도 내에서 타인의 연구정보를 사용하기 위한 최소한의 방식을 선호함을 의미한다. 이 문항 역시 집단 간의 별다른 차이는 보이지 않았다.

〈그림 20〉은 정보이용자가 원하는 오픈액 세스 환경에 관한 분석이다.

오픈액세스 환경을 가정할 때, 연구자가 이 용자의 입장에서 다른 연구자들의 연구정보를 어떠한 방식으로 이용하기를 원하는지를 살펴 본 결과이다. 응답자의 $90 \%$ 가 인용 표시를 하 지 않는 표절 금지를 택함으로써, 대부분의 연 구자들은 다른 연구자의 논문에 대한 출처의 명확한 표기만을 조건으로 자유롭게 연구정보 를 사용하기를 원하고 있다는 것을 알 수 있다.

\section{3. 결론}

조사 결과, 국내 연구자들에게 있어서 '오
픈액세스'에 대한 인식은 아직은 미비한 것으 로 나타났다. 반면, 저작권이 침해되지 않는 범위 내에서 명확한 출처를 밝히고 합법적인 목적으로 연구물을 사용한다면 오픈액세스 활 동에 참여할 의사를 가지고 있는 것으로 나타 나, 긍정적인 시사점을 제공하고 있었다. 이렇 게 본다면 적절한 수준의 저작권 지침과 라이 선스의 마련과 산재되어 있는 연구성과물의 원활한 관리와 접근 및 활용을 극대화시킬 수 있는 연구정보관리 체제의 구축이 필요함을 보여주고 있다.

\section{1 저작권 관리}

현재로서는 대학, 연구소, 과제 발주기관 등이 연구자에게 명시적으로 연구성과물의 저 작권의 양도를 직접 요구하고 있지 않고, 특허 에 한정하여 지적재산권의 승계를 요구하는 수준에 그치고 있다. 그러나 이렇게 구체적인 인식이 불비한 가운데 추후에 저작권과 관련 된 문제들이 전면에 부각될 가능성은 충분하 다. 연구자들이 각 기관과의 계약시 저작권에 관련된 조항을 충분히 숙지하고 그에 따라 대 처해야 할 필요가 여기에 있다. 또한 연구정보 의 유형에 따라 저작권의 소유자를 달리할 수 있으므로 이 역시 저작권 지침 마련시 명시하 여야 한다.

소속기관의 경우, 채용시 재직 중에 생산되 는 연구물에 대한 저작권 양도 계약서를 작성 하지 않았다고 해도 기본적으로 소속기관에 
일정 권리가 있다고 보아야 할 것이다. 소속기 관은 연구자와의 고용 계약시 '저작권 양도 계 약서'를 체결하여야 하며, 저작권 이양 후 연 구자에게 적절한 보상을 제시하거나, 연구자 와 소속기관의 공동소유 혹은 저작권은 연구 자에게 주되 소속기관은 라이선스를 가지는 등 기관의 특성에 따라 유동적인 대책을 마련 하여야 한다.

연구과제 발주기관의 경우는 연구과제 계약 시 전체 연구자의 $10 \%$ 가량만이 저작권 양도 계약서를 작성하기 때문에 저작권 관련 분쟁이 발생할 가능성이 존재한다. 따라서 각 기관들 은 연구자와 과제 계약시 저작권 양도에 대한 계약서를 작성하여야 한다. 하지만 발주기관이 저작권의 소유를 주장할 수 있는 것은 위탁한 연구과제의 결과물인 연구보고서에 한하며, 사 전연구물이나 사후연구물에 대한 저작권은 연 구자의 고유 권한으로 남겨두어야 한다.

학회의 경우는 대체로 저작권의 양도를 요 구하고 있으나, 이에 대한 연구자들의 인지도 는 낮은 것으로 나타났다. 이는 별도의 저작권 양도 계약서를 체결하는 것이 아니라, 논문 게 재시 자동으로 저작권이 이양되고 있기 때문 이다. 따라서 각 단위 학회들은 이러한 문제를 학회원들에게 충분히 주지시킬 수 있는 방안 을 마련하여야 한다.

연구정보의 유형에 따른 저작권 관리 문제 도 고려하여야 한다. 먼저 사전연구물의 경우, 연구수행 과정 이전에 생산된 정보를 담고 있 을 뿐만 아니라 연구자의 아이디어나 연구자
특유의 연구수행방식이 드러나는 자료이므로 사전연구물의 저작권은 연구자의 고유 권한으 로 남겨두어야 할 것이다. 또한 사후 연구물의 경우 연구과제 수행 완료 후 생산된 최종보고 서를 축약 또는 수정, 보완하여 작성된 연구물 이므로 그 저작권 또한 연구자 본인에게 있다 하겠다. 하지만 이 작업은 연구과제 완료 이후에 이루어져야 하며, 진도보고서(Progress Report) 를 논문으로 발표할 경우에는 과제 발주기관 의 동의를 얻어야 한다. 이는 연구과제의 주제 나 목적 등 세부사항이 공개됨으로 인해 연구 자와 연구과제 발주기관 사이에서 일어날 수 있는 오해의 소지를 없애기 위해서이다. 한편, 연구보고서는 연구자가 발주기관으로부터 연 구과제를 위탁받아 생산하게 된 최종결과이므 로, 연구보고서의 저작권은 마땅히 발주기관 에서 관리해야 한다.

\section{2 리포지터리를 통한 연구성과물 관리}

리포지터리 구축에 있어서 핵심은 저작권은 인정하되 저작권의 장벽은 낮추면서, 정보생 산자와 이용자의 접근을 용이하게 하는 것이 다. 리포지터리 운영 소프트웨어에 있어서 연 구성과물에 대한 라이선스 구성요소를 저자의 의도에 맞게 선택·적용할 수 있어야 하며, 연 구정보의 무단 사용을 막아 저작권자의 권리 를 보호하기 위한 기능이 마련되어야 한다. 또 한 기관 내 모든 연구자의 연구정보에 대한 통 합 검색 기능이 제공되어야 한다. 
수집대상 연구성과물의 범위에 관한 조사 결과, 연구진행 과정과 정보공개 비율은 반비 례하는 것으로 나타났다. 이는 연구자들이 연 구 초기에 생성된 자료일수록 공개를 꺼린다 는 것이다. 따라서 리포지터리에서 사전연구 물을 수집하는 것은 현실적으로 어려울 것이 다. 수집할 자료는 연구보고서 이후의 것으로 범위를 정하되, 기관 내 연구자들의 신상정보 데이터베이스를 구축하여 소장하는 것이 바람 직하다. 이는 연구자의 연구이력과 연구성과 물에 대한 초록을 제시하는 데이터베이스로서 사전연구물을 필요로 하는 이용자가 있을 경 우 연구자에게 개별적으로 연락하여 자료를 제공받을 수 있는 시스템을 구축하는 것이다. 물론 이용자는 자신의 신분과 사전연구물을 이용하고자 하는 목적을 밝혀야하며, 연구자 는 사용목적이 타당하지 못하다고 판단될 경 우 자료 제공을 거부할 것이다.

반면 연구보고서나 사후연구물의 수집은 연 구자가 제시한 라이선스 제한 사항을 준수한 다면 그다지 어렵지 않을 것으로 보인다. 정보 사용 전에 회원가입 절차를 거쳐 이용약관을 인지시키고 이용자의 정보이용에 대한 기록을 보존하여 리포지터리 내의 연구정보를 유출을 방지해야 한다. 또한 이러한 시스템상의 개인 정보 보안에 유의해야 할 것이다. 기관 리포지 터리는 정보생산자인 동시에 정보이용자인 연
구자들의 자발적인 참여와 협력이 매우 중요 하다. ${ }^{3)}$ 이는 연구자 스스로 정보공유에 대한 필요성을 깨닫고, 자신의 연구성과물을 셀프 아카이빙해야 하기 때문이다. 조사 결과 많은 연구자들이 '본인의 연구실적을 높이기 위해' 연구에 임한다고 답하였다. 이렇게 볼 때, 리 포지터리에 자신의 연구성과물을 등록하는 연 구자들에 한해 가산점을 준다던가, 인센티브 지급 등의 혜택을 주는 것도 고려해 볼 수 있 다. 연구자와의 고용 계약 시 고용이후에 생산 된 연구정보를 필수적으로 리포지터리에 등록 하도록 하는 '리포지터리 등록 계약서'를 함께 체결하는 방법도 있다. 이는 소속기관에 의해 지원된 과제의 성과물이나 외부로부터 지원된 위탁 연구과제의 사전 - 사후 연구물에 해당되 는 내용이다. 위탁 연구과제의 경우 연구보고 서의 저작권은 연구과제 발주기관에 귀속되어 있으므로 이것은 발주기관의 리포지터리에 제 공해야 한다. 그러나 연구자의 소속기관은 이 연구보고서의 간단한 초록을 제공한다거나 이 용자의 편의를 위해 원문을 제공하는 발주기 관 리포지터리의 홈페이지 주소를 링크하는 등의 방안도 마련해야 한다.

\section{참고문헌}

과학기술부. 2003. 『생명공학백서 - 국내외 생

3) 2007년 8월부터 학술진흥재단에서 운영중인 “기초학문자료센터(http://www.krm.or.kr)"의 경우가 이에 해당된 다. 이 센터는 학진이 발주한 과제의 연구성과물로 구축된 $\mathrm{DB}$ 인데, 연구보고서와 사후연구물의 경우 의무등록이지 만, 사전연구물의 경우 자료수집과 연구자의 동의확보가 상대적으로 어려운 것으로 알려져 있다. 
명공학 관련 정부 정책 및 연구동향』. 경 기: 과학기술부.

신은자. 2001. 전자저널의 가격모형과 가격책정 현황에 관한 연구. 『한국문헌정보학회지』, 35(2): 151-170.

안부영, 송치평. 2005. 생명과학 문헌정보 네트 워크 프로토타입 개발. 『정보관리연구』, 36(2): 125-151.

윤희윤. 2005. 학술정보 유통위기 및 해소전략의 해부. 정보관리연구』, 36(1): 1-32. 이상호 외. 2004.『오픈액세스기반 과학기술 지 식정보자원 공유체제 구축에 관한 기초연 구』. 서울: 한국과학기술정보연구원. 이수상. 2003. 디지털 도서관의 개방 접근에 관한 연구.『한국도서관정보학회지』, 34(3): 93-110.

이수상. 2004. 학술정보유통에 있어 OAI 프로토 콜의 적용에 관한 연구.『한국도서관정보 학회지』, 35(2): 219-241.

원세연. 2000. 생물정보학이란 무엇인가? 『과학 기술정책』, 125: 71-78.

장금연. 2004. 학술정보유통을 위한 레포지터리 적용 방안 연구. 『한국문헌정보학회지』, 38(4): 291-310.

정경희. 2005. 학술 커뮤니케이션 전환 과정에 대한 이해: 오픈액세스 모델 적용 시도를 통한 고찰. 『정보관리학회지』, 22(3): 183-199.

최은주. 2000. 『디지털도서관과 사회과학정보 원』. 서울: 한국도서관협회.
최재황, 조현양. 2005. 오픈액세스 운동이 동향 과 학술적 이해관계자의 대응전략. 『정보 관리학회지』, 22(3): 307-326.

최희윤. 2005. 연구 프로세스 기반 지식관리 프레 임워크 구축에 관한 연구.『정보관리연구』, 36(2): 73-98.

황혜경, 김혜선, 최선희. 2004. 오픈액세스 기반 지식정보저장소 구축에 관한 연구. 『한국 비블리아』, 15(1): 1-26.

Evans, G. 2000. Edward. Developing Library and Information Center Collections. Greenwood: Libraries Unlimited.

Julie E. Cohen, 신동룡 역. 2001. 정보권리와 지적자유. 『법학연구』, 11(1): 185-215.

OECD. Science, Technology and Innovation for the 21st Century. Meeting of the OECD Committee for Scientific and Technological Policy at Ministerial Level, 29-30 January 2004 - Final Communique. [cited 2008. 11. 01]. $\langle$ http://www.oecd.org/document/0 ,2340,en_2649_34487_25998799_1_ 1_1_1,00.html $>$.

Sabo, Martin Olav. 2003. Congressman Sabo Introduces Legislation Making Federally Funded Research Accessible to the public. [cited 2008. 11. 01]. 〈http://sabo.house.gov/index.asp? Type $=$ B_PR\&SEC $=\{8$ DBF09BA - C7 1 
9-4B8B-8FIE-98D0634D91DC\}\&D

$\mathrm{E}=\{9 \mathrm{EF} 29 \mathrm{~B} 4 \mathrm{c}-\mathrm{A} 787-424 \mathrm{~F}-9860-4$ 2DD770F2590\}>.

UK. House of Commons Science and Technology Committee. 2004. Scientific Publications : Free for all? [cited
2008. 11. 01].

$\langle$ http://72.14.203.104/search?q=c ache:eI3zDX-uNBwJ:www. publicat ions. parliament.uk/pa/cm200304/c mselect/cmsctech/399/399. pdf+fre $\mathrm{e}+$ for + all\&hl=ko $\rangle$. 